\title{
Glucose Homeostasis Is Dysregulated in Ducks Infected with Duck Hepatitis B Virus
}

\author{
Yanlian Tan ${ }^{a}$ Jianxiang Liu ${ }^{a}$ Yingjian Qin ${ }^{b}$ Bin Liang ${ }^{a}$ Yunyan Gu ${ }^{a}$ \\ Lilan Liang $^{\mathrm{a}}$ Lili Liu $^{\mathrm{a}}$ Yongming Liu ${ }^{\mathrm{a}}$ Heling Su ${ }^{\mathrm{a}}$ \\ aDepartment of Biochemistry and Molecular Biology, Guilin Medical University, Guilin, China; ${ }^{b}$ Division of Medical \\ Laboratory Science, Guilin Maternal and Child Health Care Hospital, Guilin, China
}

\section{Keywords}

Duck hepatitis B virus · Infection · Glucose homeostasis .

Dysregulation · Glucose tolerance test

\begin{abstract}
Introduction: The association between hepatitis B virus (HBV) infection and the development of diabetes remains controversial. This study examined the effect of HBV infection on glucose homeostasis using a duck HBV (DHBV) model. Methods: Plasma DHBV DNA was detected by quantitative polymerase chain reaction (PCR). Tissue infection of DHBV was determined by detecting DHBV covalently closed circular DNA (cccDNA) with a method of rolling circle amplification combined with cross-gap PCR, and verified by fluorescence in situ hybridization assay. An intravenous injection glucose tolerance test (GTT) was used to analyze the effect of DHBV infection on glucose tolerance. Results: Of the finally included 97 domestic ducks, 53 (54.6\%) were congenitally infected by DHBV. The positive rate of DHBV ccCDNA in the liver, kidney, pancreas, and skeletal muscle of the infected ducks was $100,75.5,67.9$, and $47.2 \%$, respectively. The DHBV-infected ducks had higher blood glucose levels at 15 and 30 min post-load glucose $(p<0.01$ and $p<0.001$, respectively) in the GT, much more individuals with greater glucose area under curve $(p<0.01)$, and a $57 \%$ impaired glucose tolerance (IGT) rate, as compared with noninfected controls.
\end{abstract}

In addition, the subgroups of the infected ducks with DHBV cccDNA positive in skeletal muscle maintained the higher blood glucose level up to $2 \mathrm{~h}$ post-load glucose during the GTT and had a 76\% IGT rate. Conclusion: These results suggest that DHBV intrahepatic and extrahepatic infection impairs glucose tolerance, and thus evidence the association of DHBV infection with the dysregulation of glucose metabolism.

(c) 2021 S. Karger AG, Basel

\section{Introduction}

Hepatitis B virus (HBV) infection is a major threat of public health worldwide, with an estimated chronic infection of 257 million people and a leading cause of cirrhosis and hepatocellular carcinoma, 2 conditions with about 887,000 deaths annually [1]. HBV belongs to the family of Hepadnaviridae that are widely prevalent in vertebrates from fish to humans, and there are 5 genera: Parahepadnaviru, Metahepadnavirus, Herpetohepadnavirus, Avihepadnavirus, and Orthohepadnavirus [2]. The animal-hosting woodchuck hepatitis virus of Orthohepadnavirus and duck HBV (DHBV) of Avihepadnavirus are commonly used, as experimental models, in studies of human HBV infection. The viruses of Hepadnaviridae family share similar viron shape and genome homology.

Correspondence to:

Heling Su, helingsu@glmc.edu.cn 
They are partly double-stranded DNA viruses with approximately 3,200 base pairs of the viral genome. The viral genome does not have a direct function as a template for RNA transcription but can be converted to covalently closed circular DNA (cccDNA) in the cell nucleus [3]. With the cccDNA as a template of transcription, the hepadnaviruses complete their replication cycle by creating an RNA intermediate, the pregenomic RNA, and reverse transcription of the RNA into viral DNA [4]. The hepadnaviruses primarily infect hepatocytes, causing liver inflammation, and in sometimes naturally infect extrahepatic tissues. In humans, the HBV DNA has been detected in diverse tissues including liver, pancreas, thyroid gland, adrenal glands, kidneys, spleen, lymph nodes, testes, bone marrow, skin, colon, stomach, and cerebrospinal fluid during acute and chronic HBV infection phases [5-7]. Extrahepatic infection of woodchuck hepatitis virus and DHBV was also found in the animals with the virus infection $[8,9]$.

The liver has a key role in glucose metabolism and adequate liver function is essential to maintain glucose homeostasis. Diabetes, another major concern in public health, may be a complication of end-stage liver disease, especially in patients with chronic hepatitis virus infection [10]. Studies have revealed that chronic viral hepatitis $B$ is associated with insulin resistance $[11,12]$ and may be potential risk factor for development of type 2 diabetes mellitus [13]. In a recent study of a large population at low risk of diabetes, higher incidence of diabetes mellitus was found in the hepatitis B surface antigen (HBsAg) positive participants as comparing with the HBsAg negative ones, and diabetes is suggested to be an additional metabolic complication of HBV infection [14]. Moreover, some newly investigations highlighted HBV infection links to gestational diabetes mellitus [15-17], as well as to insulin resistance in patients with chronic hepatitis B combined with nonalcoholic fatty liver disease [18]. Nevertheless, the relationship between HBV infection and the development of diabetes thus far remains controversial, owing to no association of HBV infection with type 2 diabetes mellitus was observed in several studies $[19,20]$. Evidence for verifying HBV infection impairs glucose metabolism, leading to incidence of diabetes mellitus is thus particularly necessary.

The maintenance of glucose homeostasis depends on the regulations of both liver and extrahepatic tissues such as pancreas, kidneys, and skeletal muscle via multiple physiological processes including insulin secretion, cellular glucose uptake, glycogenolysis, gluconeogenesis, and glucose reabsorption. Hepatitis virus infection may interfere with the normal function of these organs and to date, however, the role of HBV in glucose homeostasis is still unclear. Thus, by using a duck model, the present study has detected intrahepatic and extrahepatic infection of DHBV, analyzed the influence of the DHBV intrahepatic and extrahepatic infection on blood glucose level under fasting and glucose tolerance test (GTT) conditions, and thereby determined the association of DHBV infection with impaired glucose homeostasis.

\section{Materials and Methods}

\section{Experimental Animals}

A total of 100 domestic ducks (Anas platyrhyncha domestica) with the same genetic background were purchased at day 1 posthatch from a poultry farm located in the Guilin Prefecture of Guangxi Zhuang Autonomous Region, China. Congenital infection of DHBV was common in the ducks in the region. The ducks were held at the animal house at Guilin Medical University (GMU) when they were obtained. Three of the ducks died during feeding. The remaining 97 ducks, consisting of 41 males and 56 females were used for the experiments at age of 90 days with an average weight of $0.91 \mathrm{~kg}$.

\section{Plasma and Tissue DNA Extraction}

Whole blood samples were obtained from wing veins of the ducks and then plasma separated at $4^{\circ} \mathrm{C}$. The plasma was stored at $-80^{\circ} \mathrm{C}$ until assayed. Plasma DHBV DNA was extracted from 100 $\mu \mathrm{L}$ of the plasma using a QIAamp DNA Micro Kit (Qiagen, Hilden, Germany), according to the manufacturer's instruction.

The samples of liver, pancreas, kidney, and skeletal muscle were collected from the ducks after undergoing GTT experiment and were cut into pieces of 200-300 mg, frozen in liquid nitrogen, and stored at $-80^{\circ} \mathrm{C}$ until assayed. Tissue DHBV DNA was extracted from 40 to $60 \mathrm{mg}$ of the tissue samples using the same kit as above, and $100 \mu \mathrm{L}$ of the final volume of the extract was obtained.

\section{Plasma DHBV DNA Detection}

Plasma DHBV DNA was detected using the SYBR green quantitative polymerase chain reaction (qPCR) method as described previously [21]. Briefly, a 262 bp DNA fragment was amplified from DHBV $S$ gene for construction of standard plasmid. The amplification system contained $25 \mu \mathrm{L}$ of $2 \times$ Taq PCR Master Mix, 5 $\mu \mathrm{L}$ of plasma DHBV DNA, $0.5 \mu \mathrm{L}$ of each $10 \mathrm{~mm}$ primers Ps 1 and Ps2 (Table 1) and $\mathrm{ddH}_{2} \mathrm{O}$ to $50 \mu \mathrm{L}$ of final volume. Amplification was carried out at $94^{\circ} \mathrm{C}$ for $3 \mathrm{~min}, 35$ cycles of $30 \mathrm{~s}$ at $94^{\circ} \mathrm{C}, 40 \mathrm{~s}$ at $56^{\circ} \mathrm{C}$ and $30 \mathrm{~s}$ at $72^{\circ} \mathrm{C}$, and $7 \mathrm{~min}$ at $72^{\circ} \mathrm{C}$. The PCR products were purified with a QIAquick Gel Extraction Kit (Qiagen, Hilden, Germany) and cloned into pGEM-T Easy Vector System (Promega, Madison, WI, USA) as per the manufacturer's protocol, creating a standard plasmid pGEM-DHBV-S. The concentration of pGEMDHBV-S was determined by measuring the absorbance at $260 \mathrm{~nm}$ $\left(A_{260}\right)$, and then the $A_{260}$ unit was converted into viral genome equivalents (vge)/mL by calculations based on the following equations:

A260 $1=50 \mu \mathrm{g} / \mathrm{mL}, 1 \mathrm{bp}=660 \mathrm{~g} / \mathrm{mol}$ and $(6.02 \times 1023) \times$ $(\mathrm{g} / \mathrm{mL}) /($ DNA length $\times 660)=\mathrm{vge} / \mathrm{ml}$. 
Table 1. Primers used in the PCR and RCA for DHBV detection

\begin{tabular}{|c|c|c|c|}
\hline Name & Sequence & Position $^{a}$ & Polarity \\
\hline \multicolumn{4}{|c|}{ Primers for $q P C R$} \\
\hline Ps1 & 5'-AGCTGGCCTAATCGGATTAC-3' & nt1319-1338 & Sense \\
\hline Ps2 & 5'-TGTCCGTCAGATACAGCAAG-3' & nt1581-1562 & Antisense \\
\hline \multicolumn{4}{|c|}{ Primers for $R C A$} \\
\hline RCA1 & 5'-AATTCTCGAAATA*C*T-3' & nt1361-1375 & Sense \\
\hline RCA2 & 5'-GATCCGAGGGCAG*'T*A-3' & nt1668-1654 & Antisense \\
\hline RCA3 & 5'-CCAATGGGAGTCG*G*T-3' & nt1610-1624 & Sense \\
\hline RCA4 & 5'-TACACGTGGCAAA*G*G-3' & nt2164-2150 & Antisense \\
\hline RCA5 & 5'-CTGTACCTTTGCC**A*C-3' & nt2145-2159 & Sense \\
\hline RCA6 & 5'-CCGCAATTCTTTC*C*A-3' & nt1912-1898 & Antisense \\
\hline RCA7 & $5^{\prime}$-TAGAAGAAGAAAA* ${ }^{*}{ }^{*} \mathrm{~T}-3^{\prime}$ & nt267-281 & Sense \\
\hline RCA8 & $5^{\prime}$-AGTAAATGGTAAC*A*C-3' & nt2005-1991 & Antisense \\
\hline \multicolumn{4}{|c|}{ Primers for gap PCR } \\
\hline PK1 & 5'-CCAACACATGGCGCAATATC -3' & nt2180-2199 & Sense \\
\hline PK2 & 5'-GCCTAAAGGTATCTCCTCAG -3' & nt2958-2939 & Antisense \\
\hline
\end{tabular}

PCR, polymerase chain reaction; qPCR, quantitative PCR; RCA, rolling circle amplification. ${ }^{\text {a }}$ Related to the DHBV sequence (GenBank accession no. JX469896). * Sulfur modifications.

The qPCR was performed with a Bio-Rad CFX96 touch qPCR machine. The $25 \mu \mathrm{L}$ of reaction system contained $12.5 \mu \mathrm{L}$ of $2 \times$ SYBR Premix Ex Taq (TaKaRa Bio, Dalian, China), $5 \mu \mathrm{L}$ of plasma DHBV DNA extracts, $0.5 \mu \mathrm{L}$ of each $10 \mathrm{~mm}$ primers Ps1 and Ps2 (Table 1), $0.5 \mu \mathrm{L}$ of $50 \times$ Rox Reference Dye II and dd $\mathrm{H}_{2} \mathrm{O}$ to $25 \mu \mathrm{L}$ of final volume. The conditions for the QPCR were as follows: initial denaturation for $3 \mathrm{~min}$ at $94^{\circ} \mathrm{C}$ followed by 40 cycles of $30 \mathrm{~s}$ at $94^{\circ} \mathrm{C}, 40 \mathrm{~s}$ at $56^{\circ} \mathrm{C}$ and $30 \mathrm{~s}$ at $72^{\circ} \mathrm{C}$ and final extension for $5 \mathrm{~min}$ at $72^{\circ} \mathrm{C}$. A series of 10 -fold diluted standard plasmid pGEM-DHBV$S$ was included in each assay to generate a standard curve. Each sample was determined 3 times, and a DHBV negative sample determined by DHBsAg detection via enzyme-linked immunosorbent assay was added in each assay as a negative control.

\section{Tissue DHBV cccDNA Detection}

DHBV cccDNA was detected by applying a method of rolling circle amplification (RCA) combined with cross-gap PCR described previously [22]. In brief, the RCA was firstly performed in a $10 \mu \mathrm{L}$ of annealing system containing: $1 \times$ phi29 DNA polymerase buffer (Fermentas, Waltham, MA, USA), $200 \mathrm{ng}$ of total DNA, and the 8 RCA primers (Table 1) at a concentration of 0.5 $\mu \mathrm{M}$ each. The annealing conditions were $95^{\circ} \mathrm{C} 3 \mathrm{~min}, 50^{\circ} \mathrm{C} 15 \mathrm{~s}$, $30^{\circ} \mathrm{C} 15 \mathrm{~s}, 20^{\circ} \mathrm{C} 10 \mathrm{~min}$, and then in ice for $10 \mathrm{~min}$. The followed amplification was performed in a $20 \mu \mathrm{L}$ of amplification system: 10 $\mu \mathrm{L}$ of the annealing mixtures above were combined with $10 \mu \mathrm{L}$ of reaction mixture containing: $1 \times$ phi29 DNA Polymerase buffer, the 8 RCA primers (Table 1 ) at a concentration of $0.5 \mu \mathrm{M}$ each one, $0.4 \mathrm{mg} / \mathrm{mL}$ of bovine plasma albumin, $4 \mathrm{mM}$ of dithiothreitol, 2 $\mathrm{mM}$ of each dNTP, and $10 \mathrm{U}$ of the phi29 DNA polymerase (Fermentas, Waltham, MA, USA). The amplification conditions were $30^{\circ} \mathrm{C} 18 \mathrm{~h}$ and $65^{\circ} \mathrm{C}$ for $10 \mathrm{~min}$. The RCA was followed by a crossgap PCR which was implemented in a $25 \mu \mathrm{L}$ of PCR reaction system containing: $12.5 \mu \mathrm{L}$ of $2 \times$ Taq PCR Master Mix, $1 \mu \mathrm{L}$ of RCA product, $0.5 \mu \mathrm{L}$ of each $10 \mathrm{~mm}$ primers $\mathrm{Pk} 1$ and $\mathrm{Pk} 2$ (Table 1), 0.5 $\mu \mathrm{L}$ of Taq DNA polymerase and $\mathrm{ddH}_{2} \mathrm{O}$ at a final volume of $25 \mu \mathrm{L}$. Reactions were carried out at $94^{\circ} \mathrm{C}$ for $3 \mathrm{~min}, 35$ cycles of $30 \mathrm{~s}$ at $94^{\circ} \mathrm{C}$, $40 \mathrm{~s}$ at $56^{\circ} \mathrm{C}$ and $30 \mathrm{~s}$ at $72^{\circ} \mathrm{C}$, and then $7 \mathrm{~min}$ at $72^{\circ} \mathrm{C}$. The products of gap PCR were analyzed by $1 \%$ agarose gel electrophoresis.

\section{Tissue DHBV Infection Verification}

Fluorescence in situ hybridization (FISH) assay was employed for verifying tissue DHBV infection. The DHBV probe (GCCGTCAGCAGGATTGTATTTACTCGGAACA, nt585-615) used in the experiment was designed with the DHBV genome sequence (GenBank accession no. JX469898) cloned previously from a domestic duck by this laboratory, and synthesized and $5^{\prime}$-carboxyfluorescein (FAM)-labeled (Sangon Biotech, Shanghai, China). 120-200 mg of tissue specimens were paraffin-embedded and sectioned at $5 \mu \mathrm{m}$. The slides were baked for $30 \mathrm{~min}$ at $60^{\circ} \mathrm{C}$ followed sequential washes in xylene and ethanol for deparaffinization and then air-dried. The air-dried slides were incubated in proteinase $\mathrm{K}$ (Merck) solution (100 mM Tris- $\mathrm{HCl}, 50 \mathrm{~mm}$ EDTA, $1 \mu \mathrm{g} / \mathrm{mL}$ proteinase $\mathrm{K}$ ) for $20 \mathrm{~min}$ at $37^{\circ} \mathrm{C}$ followed $2 \times \mathrm{SSC}$ washes and gradient ethanol (precooled at $-20^{\circ} \mathrm{C}$ ) dehydration. Subsequently, the slides and the $5^{\prime}$-FAM-labeled DHBV probe were denatured at $75^{\circ} \mathrm{C}$ for $8 \mathrm{~min}$ in denaturation solution $(70 \%$ formamide, $2 \times \mathrm{SSC}$, $0.1 \mathrm{mM}$ EDTA) and hybridization solution (60\% formamide, $1.2 \times$ Denhardt's Solution, $12 \%$ dextran sulfate, $0.2 \mu \mathrm{g} / \mu \mathrm{L}$ yeast tRNA and $2 \mathrm{ng} / \mu \mathrm{L}$ FAM-labeled DHBV probe), respectively. The following hybridization was conducted by adding $50 \mu \mathrm{L}$ of denatured probe to each of the slides, and the slides were then gradient ethanol (precooled at $-20^{\circ} \mathrm{C}$ ) dehydrated, air-dried, and incubated at $42^{\circ} \mathrm{C}$ for $12-16$ h. $2 \mathrm{ng} / \mu \mathrm{L} 4^{\prime}, 6$-diamidino-2-phenylindole was used for staining of nuclei.

\section{Intravenous GTT}

The ducks were fasted for $16 \mathrm{~h}$ and then given intravenously a glucose load of $1 \mathrm{~g} / \mathrm{kg}$ body weight via wing veins. The solution was 


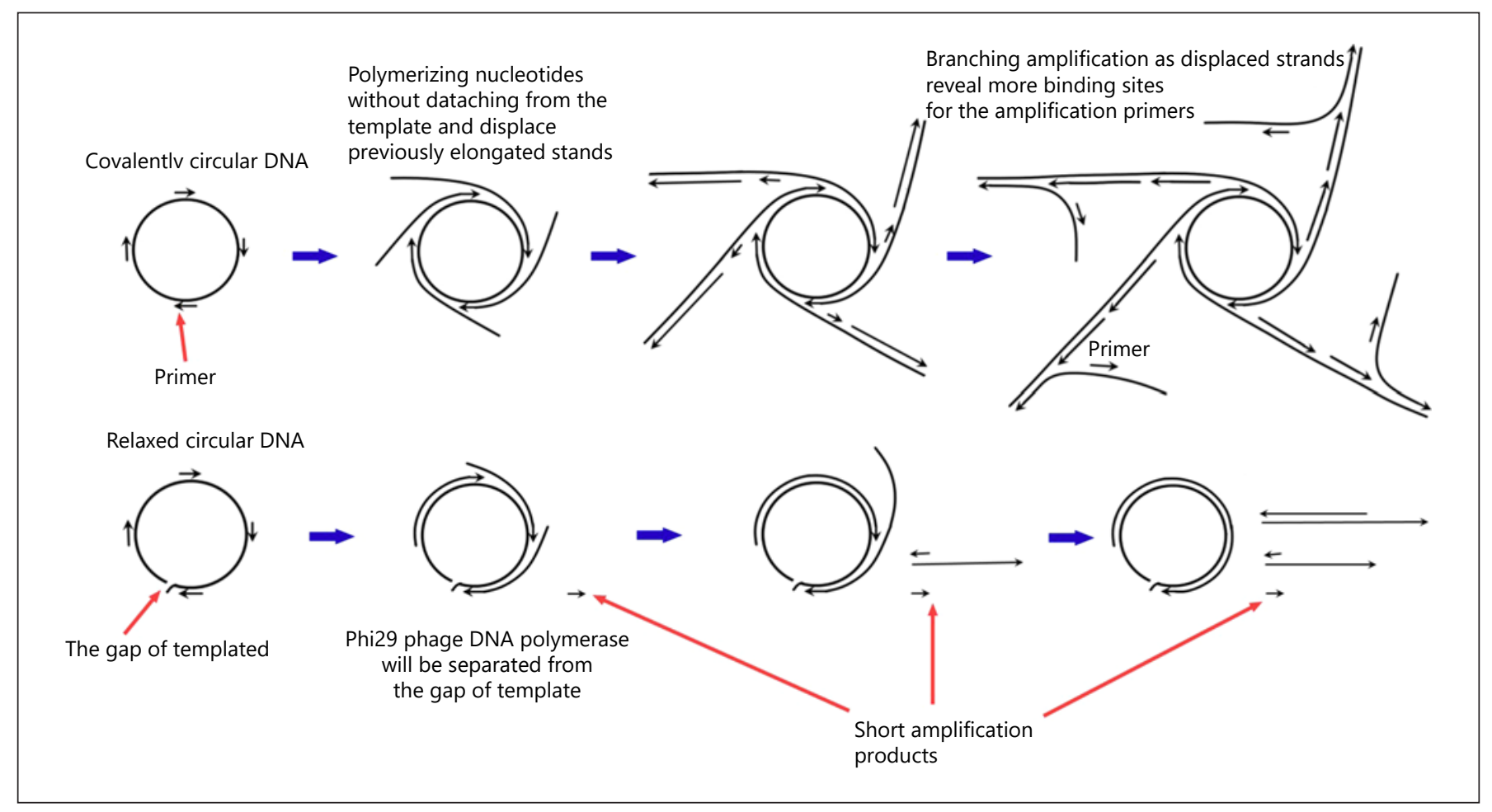

Fig. 1. Schematics of RCA.

$50 \%$ glucose $(\mathrm{w} / \mathrm{v})$ physiological saline (D- $[+]$-Glucose $\geq 99.5 \%$, Sigma-Aldrich, St. Louis, MO, USA). Blood samples were collected at $0,15,30,60,90$, and $120 \mathrm{~min}$ following the glucose injection, and the concentrations blood glucose and plasma insulin were determined immediately. After the GTT, the ducks were euthanized by intravenous injection of $0.5 \mathrm{~mL}$ of sodium phenobarbital (30 $\mathrm{mg} / \mathrm{mL}$ ). The liver, pancreas, kidney, and skeletal muscle tissues of the ducks were collected and stored as described above.

\section{Blood Glucose Assays}

Blood glucose concentrations were measured with an AccuChek Active blood glucose meter (Roche Diagnostics, Mannheim, Germany) as per the manufacturer's instructions.

\section{Statistical Analysis}

Data were expressed as mean \pm SD. Statistical analysis was performed with SPSS 18.0 software (SPSS, Chicago, IL, USA). The levels of fasting glucose and the glucose at each time point of postload glucose during the intravenous GTT (IGTT) were compared between DHBV-infected and DHBV-noninfected ducks by using a one-way analysis of variance followed by post hoc analysis. Logistic regression and receiver operation characteristic (ROC) curve analysis were used to determine the independent risk factors of impaired glucose tolerance (IGT) and their optimal cut points associated with IGT. Glucose responses during the IGTT were evaluated by estimating the total area under the curve (AUC) using the trapezoidal method. A ROC-AUC of $<0.50$ is considered worthless and $>0.60$ significance. Difference was considered to have statistical significance when the $p$ values were $<0.05$.

\section{Results}

\section{Plasma DHBV DNA Detection}

The detection of plasma DHBV with the qPCR showed that 53 of the ducks ( 24 males and 29 females) were DHBV DNA positive in serum, displaying a range of $1.02 \mathrm{E}+05-$ $7.35 \mathrm{E}+07(6.84 \pm 1.32 \mathrm{E}+06)$ vge per quantification well (vge/well) of DHBV DNA level, while 44 of the ducks (17 males and 27 females) DHBV DNA negative in serum. The infection rate of DHBV in the ducks was $54.6 \%$. This result was subsequently verified by tissue DHBV cccDNA detection (see below).

\section{Tissue DHBV cccDNA Detection}

Tissue DHBV cccDNA detection using the RCA combined with cross-gap PCR assay produced firstly a $>10 \mathrm{kp}$ of RCA product, and then a 779 bp of amplicon was amplified with RCA product as template. In contrast to cccDNA, relaxed circular DNA (rcDNA), the form of DHBV DNA in plasma, could not be used as a template to synthesize the RCA product due to the existence of the nt2508 gap in the viral DNA sequence (shown in Fig. 1), and as the result, no $779 \mathrm{bp}$ of amplicon was amplified. Thus, the analysis of the samples of DHBV positive plasma using the 
Fig. 2. Amplification of DHBV cccDNA with RCA combined with cross-gap PCR. a The raw products of RCA. $\mathrm{M}$ is a DNA marker. The blood (line $\mathrm{BL}$ ) is used as negative control, and the liver (line LI) as positive control for amplification of DHBV genome, and line PA, KI, and SM are pancreas, kidney, and skeletal muscle, respectively. b The products of cross-gap PCR amplified by using RCA product as template. cccDNA, covalently closed circular DNA.

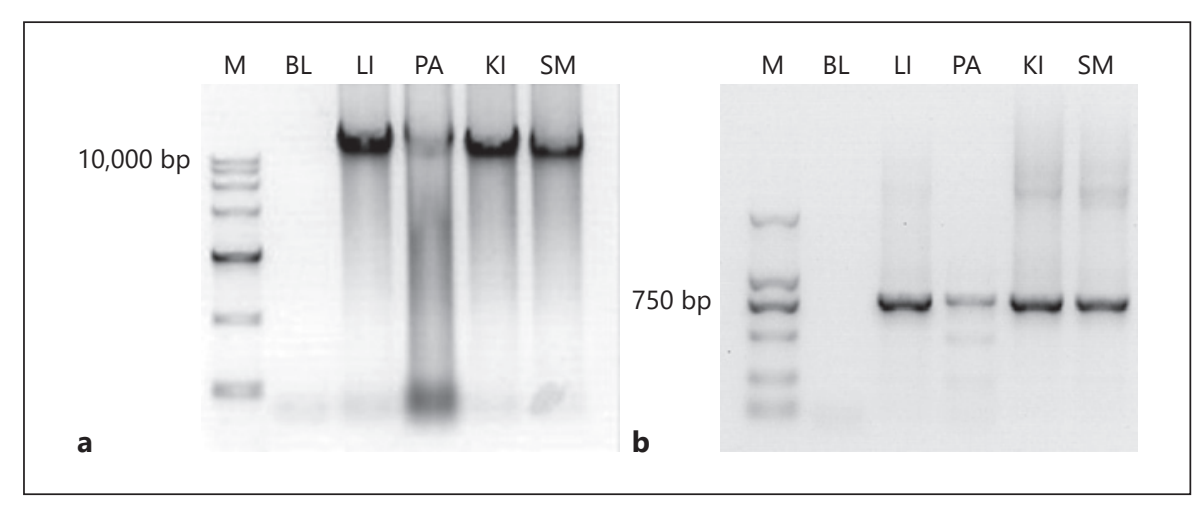

RCA combined with cross-gap PCR assay created a negative result. Figure 2 shows the amplification result of DHBV cccDNA detection of a DHBV-infected duck with the blood (rcDNA form of DHBV) as negative control, and the liver (cccDNA form of DHBV) as positive control by using the RCA combined with cross-gap PCR assay.

The detection of DHBV DNA cccDNA in the extrahepatic tissue samples showed the detected rates of the DHBV cccDNA in the kidney, pancreas, and skeletal muscle of the DHBV-infected ducks were 75.5, 67.9, and $47.2 \%$, respectively. Meanwhile, cccDNA assays were negative in all of the tissue samples from the DHBV-noninfected ducks.

\section{Tissue DHBV Infection Verification}

A few of the samples of liver, kidney, pancreas, and skeletal muscle, which were determined to be DHBV positive by RCA combined with cross-gap PCR assays, were selected for verification of the tissue infection of DHBV with FISH. The FISH assay showed that all of the selected samples of liver, kidney, pancreas, and skeletal muscle appeared hybridization spots, indicating that these tissue samples were DHBV positive (shown in Fig. 3).

\section{DHBV Infection Impairs Glucose Tolerance}

Fasting blood glucose levels were not different between the DHBV-infected ducks and the noninfected controls $(p>0.05)$. However, the blood glucose levels of the DHBVinfected ducks were significantly higher than that in the noninfected ones at 15 and 30 min post-load glucose $(p<$ 0.01 and $p<0.001$, respectively) during the IGTT (shown in Fig. 4a). AUC analysis showed that there were much more individuals with greater glucose AUC in the DHBVinfected duck group as compared with that in the group of the noninfected ones (shown in Fig. 4b). Accordingly, the ROC curve plotted with the glucose AUC of DHBV-infected duck group displayed a curve area of $0.7086 \pm$
0.05280 (95\% confidence interval $0.6051-0.8121, p<0.01$ ) with a cutoff value of $31.77 \mathrm{mmol} \times \mathrm{h} / \mathrm{L}$, and the specificity $79.55 \%$ and the sensitivity $56.60 \%$ (shown in Fig. 4c). Thirty of the 53 DHBV-infected ducks had blood glucose AUC above the cutoff point, and the IGT rate was $57 \%$.

Further investigation for the effect of extrahepatic tissue infection by DHBV on glucose tolerance showed that while the subgroups of the infected ducks with pancreas and kidneys DHBV cccDNA positive had similar glucose response to DHBV-infected duck group (shown in Fig. 5a, b), the subgroups of the infected ducks with skeletal muscle DHBV cccDNA positive maintained the higher blood glucose level up to $2 \mathrm{~h}$ post-load glucose during the IGTT (shown in Fig. 5c). In addition, all subgroups of the infected ducks with pancreas, kidneys, and skeletal muscle DHBV positive had much more individuals with greater glucose AUC in the DHBV-infected duck group as compared with noninfected controls (shown in Fig. 5d). Table 2 shows the characteristics of the ROC curves plotted with the glucose AUCs of the subgroups of the infected ducks with tissue DHBV cccDNA positive. According to the cutoff values for IGT obtained from the ROC curves, 21 of the 36 pancreas DHBV cccDNA positive ducks, 23 of 40 kidneys DHBV cccDNA positive ducks and 19 of 25 skeletal muscle DHBV cccDNA positive ducks had blood glucose AUC above the cutoff point, respectively, and their IGT rate was $58,57.5$ and $76 \%$, respectively. There was no difference of blood glucose levels among the groups of the male and female ducks, either with or without DHBV infection $(p>0.05)$.

\section{Discussion}

Although the pathogenic effects generated by the tropism of hepadnavirus for hepatocyte and extrahepatic cells could induce histological disruption and functional 


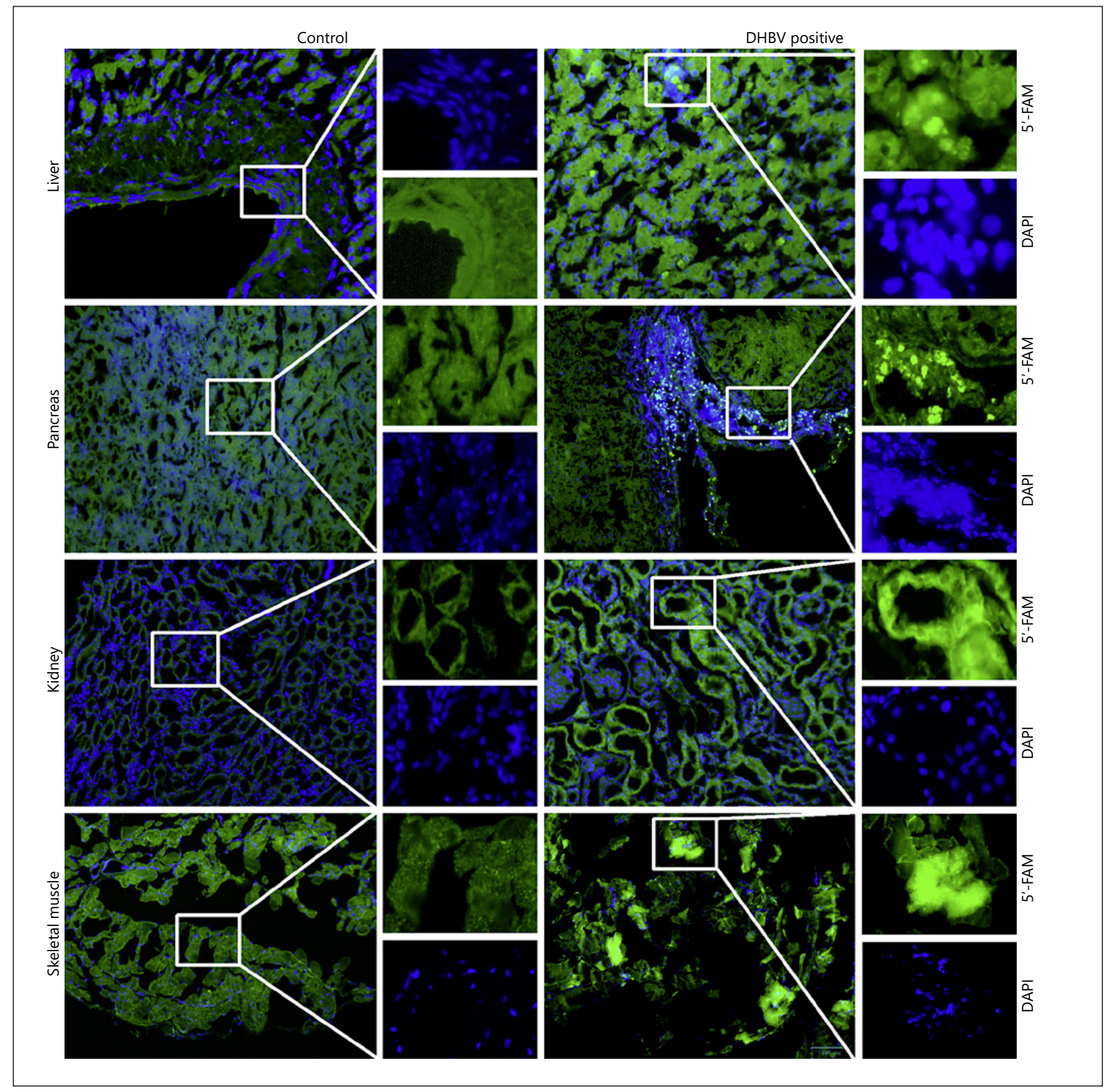

Fig. 3. FISH assay for verification of tissue infection by DHBV. DHBV was hybridized with $5^{\prime}$-FAM-labeled DHBV probe and DAPI was used for staining of nuclei. FISH, fluorescence in situ hybridization; DAPI, 6-diamidino-2-phenylindole.

impairment in the cells involved in, the association between the infection of the viruses and the impaired glucose homeostasis remains to be established. This study shows, in the DHBV model, that hepadnavirus infection associated with IGT. The blood glucose levels at 15 and
30 min post-load glucose in an intravenous injection GTT were abnormally high in the DHBV-infected ducks. The DHBV-infected duck group had much more individuals with greater glucose AUC, and accordingly had an IGT rate of $57 \%$, significantly higher than that of non- 

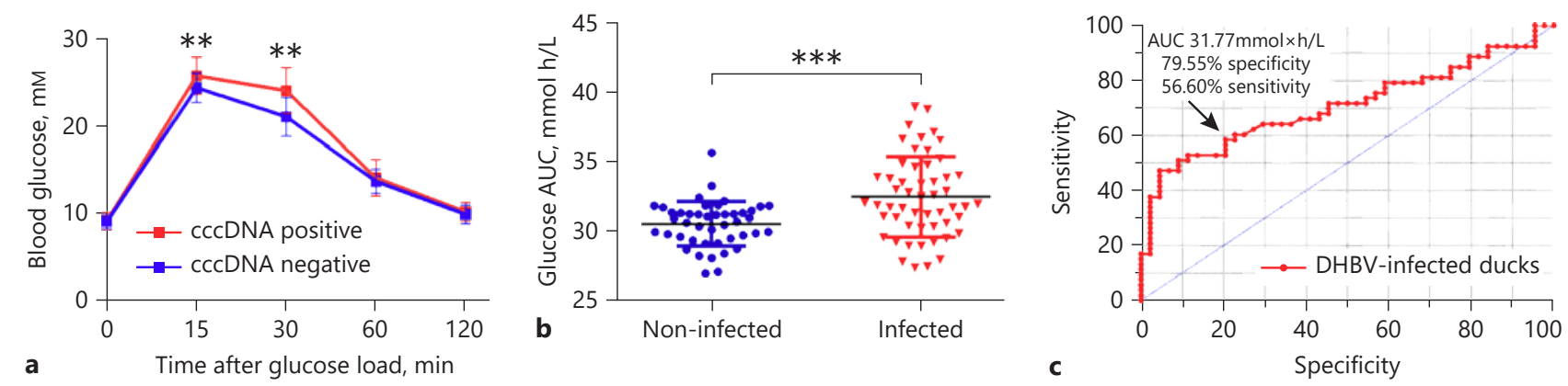

Fig. 4. Effect of DHBV infection on the blood glucose levels during the IGTT. a Blood glucose levels of both DHBV-infected duck group and noninfected one. b Individual glucose AUC of both DHBV-infected duck group and noninfected one. $\mathbf{c}$ The ROC curve plotted with the glucose AUC of DHBV-infected duck group. ${ }^{* *} p<0.01$ and ${ }^{* * *} p<0.001$. AUC, area under the curve.

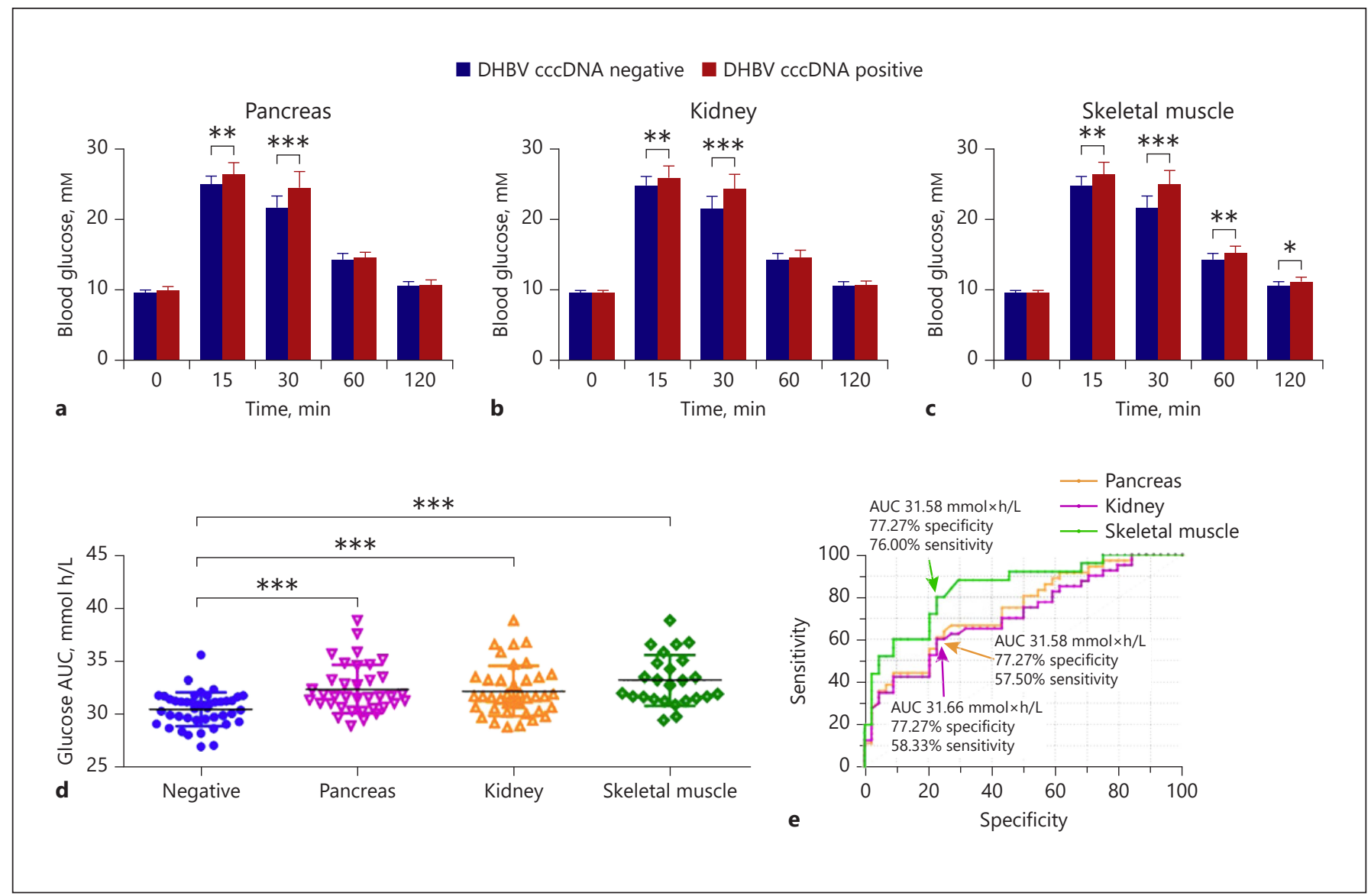

Fig. 5. Effect of tissue infection by DHBV on blood glucose levels during IGTT. Pancreas with DHBV cccDNA positive (a); kidney with DHBV cccDNA positive (b); skeletal muscle with DHBV cccDNA positive (c); individual glucose AUC of the subgroup of tissue infection by DHBV (d). e The ROC curve plotted with the glucose AUC of the subgroup of tissue infection by DHBV. ${ }^{*} p<0.05,{ }^{* *} p<0.01$ and ${ }^{* * *} p<0.001$. cccDNA, covalently closed circular DNA; IGTT, intravenous GTT; ROC, receiver operation characteristic; AUC, area under the curve. 
Table 2. The characteristics of the ROC curve plotted with the glucose AUC of tissue DHBV infected ducks

\begin{tabular}{|c|c|c|c|c|c|c|}
\hline Liver & $0.7086 \pm 0.05280$ & $0.6051-0.8121$ & 56.60 & 79.55 & $>31.77$ & $<0.001$ \\
\hline Pancreas & $0.7443 \pm 0.05473$ & $0.6370-0.8516$ & 58.33 & 77.27 & $>31.66$ & $<0.001$ \\
\hline Kidney & $0.7145 \pm 0.05592$ & $0.6049-0.8241$ & 57.50 & 77.27 & $>31.58$ & $<0.001$ \\
\hline Skeletal muscle & $0.8436 \pm 0.04955$ & $0.7465-0.9408$ & 76.00 & 77.27 & $>31.58$ & $<0.001$ \\
\hline
\end{tabular}

cccDNA, covalently closed circular DNA; ROC, receiver operation characteristic; AUC, area under the curve.

infected controls. In addition, the subgroups of the infected ducks with skeletal muscle DHBV cccDNA positive maintained the higher blood glucose level up to $2 \mathrm{~h}$ post-load glucose during the GTT and had an extremely high IGT rate of $76 \%$. These results evidence that DHBV infection impairs glucose homeostasis.

In this study, the liver is mostly preferred organ of DHBV for replication. Since the liver plays a pivotal role in glucose metabolism, severe hepatic damage may lead to the impairment of glucose homeostasis $[23,24]$. To date, the effect of HBV infection on the development of diabetes is less understood and has been mostly attributable to HBV-related hepatic cirrhosis that, however, did not occur in our tested ducks which were congenitally infected. Previous studies reported that congenitally DH$\mathrm{BV}$-infected ducks failed to produce antibodies to DHBV and significant immune-mediated injury of hepatocytes in the ducks is improbable [25]. Apparent hepatitis activity and cirrhosis rarely happen in the livers of congenitally DHBV-infected ducks [26], and thus an impaired effect due to hepatocyte infection following immune-mediated destruction of DHBV-infected cells is unlikely.

An earlier study demonstrated a downregulation effect of HBV pre-S2 protein on the gene promoter of insulin receptor, prompting that the pre-S2 protein-induced decrease of insulin receptor expression is pathogenic of HBV infection and may partially account for the etiopathogenesis of hepatogenous diabetes [27]. Hepatitis virus infection may affect glucose uptake, in which HBV pre-S2 mutant contribute to aberrant glucose uptake via the solute carrier family 2, facilitated glucose transporter member 1 (SLC2A1), also known as glucose transporter isoform-1 (GLUT1) [28]. However, the effect of wild-type pre-S2 on the glucose uptake by SLC2A1 is still not confirmed. The function of GLUT4, the key factor in glucose uptake process [29-31] and regulated by nitric oxide [32], might be impaired under the condition of $\mathrm{HBV}$ infection. It was reported that HBV X protein affected glucose homeostasis via in- ducible nitric oxide synthase activation [33]. In our study, DHBV infection appeared a marked increase in blood glucose levels during the GTT. Since skeletal muscle may also be involved in DHBV infection, as found in the present study, dysfunction of GLUT4 might be important in the mechanism underlying the disorder of glucose homeostasis by the virus infection and this needs to be investigated.

The skeletal muscle infection by the virus, to the best of our knowledge, is the first time to be demonstrated. In the study, DHBV tissue infection was examined by using the RCA combined with cross-gap PCR method established previously by our laboratory [22]. RCA was firstly used in HBV cccDNA detection in 2008, due to its specific amplification of ring templates. The cross-gap PCR produces a $779 \mathrm{bp}$ of amplicon which includes the position of nt 2508 gap, and therefore specifically amplifies the DHBV cccDNA in tissues rather than the DHBV rcDNA in blood. In addition, DHBV tissue infection was verified with FISH assay. Thus, the DHBV infection of extrahepatic tissue including skeletal muscle in this study was confirmed.

In conclusion, this study demonstrates impaired glucose homeostasis occurring in the DHBV-infected ducks, with a significant increase in blood glucose levels during the GTT. The dysregulation of glucose metabolism is associated with the virus infection in the liver and possibly in some extrahepatic tissues such as skeletal muscle, pancreas, and kidney. The mechanisms underlying HBV infection-induced glucose metabolism disorders remain unclear. Further study needs to examine the glucose metabolism-associated factors/enzymes in hepatocytes and skeletal muscle, as well as insulin production in pancreas under the virus infection conditions.

\section{Acknowledgement}

We thank Dr. Shanhong Ling, the visiting professor of GMU, for his assistance of the manuscript preparation and English editing. 


\section{Statement of Ethics}

All experiments in this study were performed by the guidelines of the Animal Experimentation Ethics Committee of the GMU (approval No. 2017-0004).

\section{Conflict of Interest Statement}

The author(s) declared no potential conflicts of interest with respect to the research, authorship, and/or publication of this article.

\section{References}

1 World Health Organization. 2020 Hepatitis B fact sheet. Available from: https://www.who.int/ en/news-room/fact-sheets/detail/hepatitis-b.

2 Magnius L, Mason WS, Taylor J, Kann M, Glebe D, Dény P, et al. Ictv report consortium. ICTV virus taxonomy profile: hepadnaviridae. J Gen Virol. 2020;101(6):571-2.

3 Ko C, Chakraborty A, Chou WM, Hasreiter J, Wettengel JM, Stadler D, et al. Hepatitis B virus genome recycling and de novo secondary infection events maintain stable cccDNA levels. J Hepatol. 2018 Dec 12;69(6):1231-41.

4 Karayiannis P. Hepatitis B virus: virology, molecular biology, life cycle and intrahepatic spread. Hepatol Int. 2017 Nov; 11(6):500-8.

5 Yoffe B, Burns DK, Bhatt HS, Combes B. Extrahepatic hepatitis $B$ virus DNA sequences in patients with acute hepatitis B infection. Hepatology. 1990 Aug;12(2):187-92.

6 Mason A, Wick M, White H, Perrillo R. Hepatitis $B$ virus replication in diverse cell types during chronic hepatitis $B$ virus infection. Hepatology. 1993 Oct;18(4):781-9.

7 Pettersson JH, Piorkowski G, Mayxay M, Rattanavong S, Vongsouvath $\mathrm{M}$, Davong $\mathrm{V}$, et al. Meta-transcriptomic identification of hepatitis $B$ virus in cerebrospinal fluid in patients with central nervous system disease. Diagn Microbiol Infect Dis. 2019 Dec;95(4):114878.

8 Freiman JS, Jilbert AR, Dixon RJ, Holmes M, Gowans EJ, Burrell CJ, et al. Experimental duck hepatitis B virus infection: pathology and evolution of hepatic and extrahepatic infection. Hepatology. 1988 May-Jun;8(3):507-13.

9 Ogston CW, Schechter EM, Humes CA, Pranikoff MB. Extrahepatic replication of woodchuck hepatitis virus in chronic infection. Virology. 1989 Mar;169(1):9-14.

$10 \mathrm{Xu}$ C, Chen J, Zhang PA. Relationship between diabetes mellitus and cirrhosis risk in chronic hepatitis B patients in Wuhan, China. Med Sci Monit. 2019 Oct 29;25:8112-9.

11 Lee JG, Lee S, Kim YJ, Cho BM, Park JS, Kim $\mathrm{HH}$, et al. Association of chronic viral hepatitis B with insulin resistance. World J Gastroenterol. 2012 Nov 14;18(42):6120-6.

12 Zhang J, Shen Y, Cai H, Liu YM, Qin G. Hepatitis $B$ virus infection status and risk of type 2 diabetes mellitus: a meta-analysis. Hepatol Res. 2015 Nov;45(11):1100-9.

\section{Funding Sources}

This study was supported by the National Natural Science Foundation of China (No. 81560341 and 81460320) and Guangxi NaturalScience Foundation ofChina(No.2018GXNSFAA138153).

\section{Author Contributions}

S.H., L.Y., and T.Y. were responsible for the conception, design, and research. L.B. and L.L. carried out the experiments. L.J., Q.Y., G.Y., and L.L. analyzed data. S.H. and L.Y. were responsible for the conclusive and final remarks.
13 Shen Y, Zhang J, Cai H, Shao JG, Zhang YY, Liu $\mathrm{YM}$, et al. Identifying patients with chronic hepatitis $B$ at high risk of type 2 diabetes mellitus: a cross-sectional study with pair-matched controls. BMC Gastroenterol. 2015 Mar 19;15:32.

14 Hong YS, Chang Y, Ryu S, Cainzos-Achirica M, Kwon MJ, Zhang Y, et al. Hepatitis B and $\mathrm{C}$ virus infection and diabetes mellitus: a cohort study. Sci Rep. 2017 Jul 4;7(1):4606.

15 Peng S, Wan Z, Lin X, Li X, Du Y. Maternal hepatitis B surface antigen carrier status increased the incidence of gestational diabetes mellitus. BMC Infect Dis. 2019 Feb 13;19(1):147.

$16 \mathrm{Wu}$ D. Correlation of viral load of hepatitis B with the gestation period and the development of diabetes mellitus. Saudi J Biol Sci. 2019 Dec;26(8):2022-5.

17 Giles ML, Davey MA, Wallace EM. Chronic hepatitis $\mathrm{B}$ infection and the risk of gestational diabetes: a cross-sectional study. BJOG. 2020 Aug;127(9):1147-52.

18 Ye J, Hu X, Wu T, Wu Y, Shao C, Li F, et al. Insulin resistance exhibits varied metabolic abnormalities in nonalcoholic fatty liver disease, chronic hepatitis $\mathrm{B}$ and the combination of the two: a cross-sectional study. Diabetol Metab Syndr. 2019;11:45.

19 Liu Y, Ye S, Xiao X, Zhou T, Yang S, Wang G, et al. Association of diabetes mellitus with hepatitis $B$ and hepatitis $C$ virus infection: evidence from an epidemiological study. Infect Drug Resist. 2019;12:2875-83.

20 Gan T, Cheng N, Ding J, Cheng Z, Zhang D, $\mathrm{Li} \mathrm{H}$, et al. Effects of hepatitis B virus infection, alanine aminotransferase, aspartate aminotransferase and gamma-glutamyl transferase on prediabetes and diabetes mellitus: a cohort study. Ann Hepatol. 2020 Mar-Apr; 19(2):197-203.

21 Su HL, Huang RD, He SQ, Xu Q, Zhu H, Mo $Z$ J, et al. [Cloning and sequence analysis of the DHBV genome of the brown ducks in Guilin region and establishment of the quantitative method for detecting DHBV]. Bing Du Xue Bao. 2013 Mar;29(2):180-4.

22 Su HL, Wang HM, Ran JY, Wang Z, Li HY, Yang Y, et al. [Establishment of a method to detect duck hepatitis $B$ virus covalently closed circular DNA based on rolling circle amplification]. Bing Du Xue Bao. 2014 Jul;30(4):382-6.
23 Custro N, Carroccio A, Ganci A, Scafidi V, Campagna P, Di Prima L, et al. Glycemic homeostasis in chronic viral hepatitis and liver cirrhosis. Diabetes Metab. 2001 Sep;27(4 Pt 1):476-81.

24 Brenner C, Galluzzi L, Kepp O, Kroemer G. Decoding cell death signals in liver inflammation. J Hepatol. 2013 Sep;59(3):583-94.

25 Cullen JM, Marion PL, Sherman GJ, Hong X, Newbold JE. Hepatic neoplasms in aflatoxin B1-treated, congenital duck hepatitis B virusinfected, and virus-free Pekin ducks. Cancer Res. 1990;50(13):4072-80.

26 Uchida T, Suzuki K, Esumi M, Arii M, Shikata $T$. Influence of aflatoxin B1 intoxication on duck livers with duck hepatitis B virus infection. Cancer Res. 1988 Mar 15;48(6):1559-65.

27 Ji D, Han P, Zhang J, Shao Q, Liu Y, Wang L, et al. [Down-regulating effect of hepatitis $B$ virus pre-S2 protein upon insulin receptor gene promoter]. Zhonghua Yi Xue Za Zhi. 2009 Nov 24;89(43):3069-73.

28 Teng CF, Hsieh WC, Wu HC, Lin YJ, Tsai HW, Huang W, et al. Hepatitis B virus pre-S2 mutant induces aerobic glycolysis through mammalian target of rapamycin signal cascade. PLoS One. 2015;10(4):e0122373.

29 Richter EA, Hargreaves M. Exercise, GLUT4, and skeletal muscle glucose uptake. Physiol Rev. 2013 Jul;93(3):993-1017.

30 Vlavcheski F, Naimi M, Murphy B, Hudlicky T, Tsiani E. Rosmarinic acid, a rosemary extract polyphenol, increases skeletal muscle cell glucose uptake and activates AMPK. Molecules. 2017 Oct 7;22(10):1669.

31 Xiong H, Zhang S, Zhao Z, Zhao P, Chen L, Mei Z. Antidiabetic activities of entagenic acid in type 2 diabetic $\mathrm{db} / \mathrm{db}$ mice and $\mathrm{L} 6$ myotubes via AMPK/GLUT4 pathway. J Ethnopharmacol. 2018;211:366.

32 Jiang H, Torregrossa AC, Potts A, Pierini D, Aranke M, Garg HK, et al. Dietary nitrite improves insulin signaling through GLUT4 translocation. Free Radic Biol Med. 2014 Feb; 67:51-7.

33 Shin HJ, Park YH, Kim SU, Moon HB, Park $\mathrm{DS}$, Han $\mathrm{YH}$, et al. Hepatitis B virus X protein regulates hepatic glucose homeostasis via activation of inducible nitric oxide synthase. J Biol Chem. 2011 Aug 26;286(34):29872-81. 